\title{
The world is getting smaller
}

\author{
Steven D. Schwaitzberg
}

Published online: 11 January 2012

(C) Springer Science+Business Media, LLC 2012

"The world is getting smaller" and with that SAGES today is truly an international society more than ever. Although based in the United States, there are more than 1,000 international members (from Europe, Asia, the Americas, and even Africa), hundreds of international abstract submissions yearly, and a dozen international outreach programs. I would like to take this opportunity to share with you some of these activities.

\section{SAGES Go Global}

Shouldn't everyone have access to well-established surgical techniques aimed at reducing burden and discomfort associated with surgical procedures? Many think so, but the challenges of extending minimally invasive surgery (MIS) beyond the wealthier countries are considerable. Born out of the early work of Ramon Berguer, who conducted basic laparoscopic training in rural settings in Latin America, SAGES Go Global program is now led by Horacio Asbun and capably staffed by Jacqueline Narvaez. The mission of the Global Affairs Committee is: To promote global collaboration and exchange of knowledge to optimize patient care. SAGES members who have donated their time and expertise "in country" to help train surgical teams around the world during the past few years include: Horacio Asbun, Ramon Berguer, Sam Finlayson, Mark Pleatman, Julio Teixeira, Ian Soriano, Raymond Price, Suzanne

S. D. Schwaitzberg

Cambridge Health Alliance, Cambridge, MA, USA

S. D. Schwaitzberg $(\bowtie)$

Harvard Medical School, Boston, MA, USA

e-mail: sschwaitzberg@challiance.org
Yoder, W. Scott Melvin, Jeff Hazey, Kevin Reavis, Brian Smith, Mike Marohn, Ted Trus, Alex Perez, Klaus Thaler, David Earle, and Allan Okrainec (Figs. 1, 2). Mission success also is dependent on folks who work in the background. Working stateside on these projects were SAGES members who supported these efforts behind the scenes working on presentations and during our teleconferences into the sites: Edgar Figueredo, Raul Rosenthal, Brant Oelschlager, Oznan Miereles, Michael Brunt, Jose Martinez, Danny Scott, Desmond Birkett, and Tonia Young Fadok. Finally, I would also like to express my thanks to those allied health members who help round out and refine the team training aspect of these programs: Denise Puno, RN, Kelly Reavis, MPH, W. Cody Alley, and Allison Wagner, RN. On many fronts SAGES has become regarded around the world as a "can-do" society. The talents and energy of SAGES members is unequaled, which also is true of the SAGES staff. Jaqueline Narvaez, Vannessa Cheung, and Marybeth Balon have used their considerable organizational skills to make all of this happen on time and within budget. The goals for 2011 were to conduct at least three courses and launch an outcomes database to assist with benchmarking the success of each location. After each course, we must find a way to build an academic relationship with each local institution to encourage sustainability and continued progress. Tentative locations being considered this year are Mongolia, Tanzania, and South America. The database is almost complete and will be ready to launch in 2012 .

Since 2009 the courses that have taken place are:

May 17-21, 2009

Jorge Reategui Hospital

Piura, Peru

Course: Basic Laparoscopy 


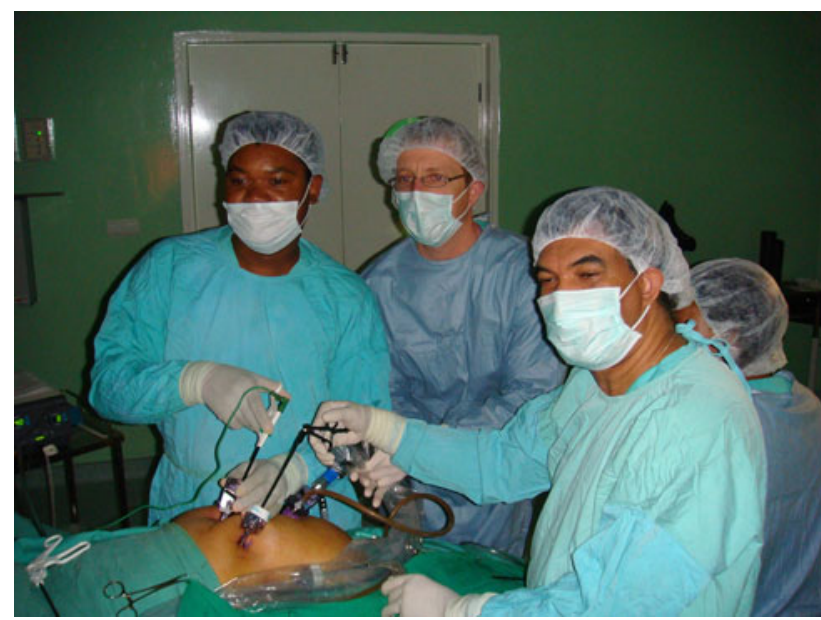

Fig. 1 Jeff Hazey, MD, teaches surgical technique in Cape Verde

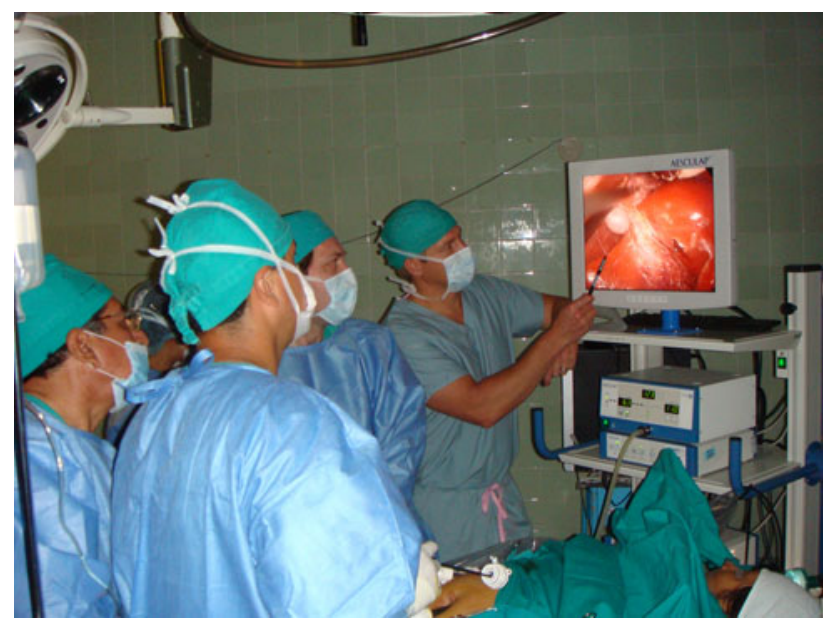

Fig. 2 Kevin Reavis, MD, points out critical anatomy in Piura Peru

June 20-25, 2010

Pingchang Hospital (with Support from the University Hospital in Shanghai, China)

Pingchang, China

Course: Basic Laparoscopy

August 23-27, 2010

\section{Zamboanga Medical Center}

Zamboanga, Philippines

The course was well received by the Philippine Association of Laparoscopic and Endoscopic Surgery (PALES). SAGES also partnered with the Buddhist Compassion Relief Tzu Chi Foundation and the SAGES Foundation for support.

\section{January 17-23, 2010}

Pingchang Hospital (with Support from the University Hospital in Shanghai, China)

Pingchang, China

Course: Basic Laparoscopy

\section{June 23-July 1, 2011}

Regional Diagnostic and Treatment Center

Uvurkhangai Aimag, Mongolia

Course: Basic Laparoscopy

SAGES partnered up with the Swanson Family Foundation (SFF). They provided ground support, equipment support, lodging, and additional support staff, i.e., Biotech, anesthesiologist, nurse, and scrub tech.

Sites from around the world apply to SAGES for training. A detailed process of evaluation is initiated. The challenges of training MIS techniques in a constrained environment are many, not the least of which is sustainability. The careful site selection process strives to optimize potential long-term success. Sadly many places are still not capable of supporting a sustainable MIS program. Where opportunities exist, we have learned the value of local commitment and the realistic biomedical support needed to create an enduring program. Because on-site training time is a precious commodity, we leverage some of our existing tools, such as The Fundamentals of Laparoscopic Surgery (FLS). Necessity is truly the never-ending mother of invention. SAGES Communication Committee Chairman, Allan Okrainec, demonstrated that FLS skills could be taught and proctored utilizing Skype as a costeffective video transmission technology (Fig. 3). This methodology has been employed effectively in China, Latin America, and Africa, once again making the world a smaller place. Challenges remain with teaching and assessing the didactic portion of the FLS program, but I will return to that later.

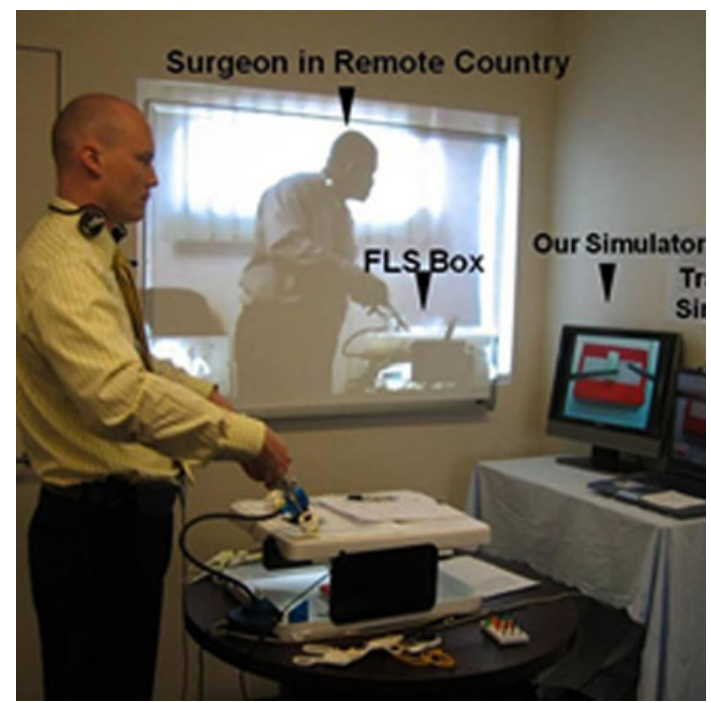

Fig. 3 FLS skills are taught by Allan Okrainic, MD, in real time over a web-based connection 


\section{SAGES International Webcast}

This activity brings value to our International Membership and creates SAGES awareness worldwide. The webcasts also are used as a tool to enhance the educational offering and promote academic relationships with International Societies and Institutions. We have seen amazing growth in the viewing audience. In 2006, we had 300 participants with only five countries participating. In 2011, we had more than 1,800 viewers and more than 20 countries online! (Azerbaijan, Bahrain, Brazil, Bosnia, China, Colombia, Herzegovina, Hong Kong, India, Iran, Japan, Korea, Mexico, Portugal, Peru, Philippines, Romania, Saudi Arabia, United Arab Emirates, U.S. Military, and Canadian Military). Web-based live video transmission is certainly making the world a smaller place.

\section{International Fellow Award}

The purpose of this award is to provide outstanding investigators with the opportunity to gather experience, training, and expertise from some of the many courses that SAGES has to offer at the annual meeting. Recipients are selected from among the top-ranking podium, poster, or video presentations at the annual SAGES meeting. In 2011, SAGES awarded four International Fellow Awards in the amount of $\$ 2,500$ each.

\section{SAGES other societies around the world}

SAGES is a member of International Federation of Societies of Endoscopic Surgery (IFSES). IFSES chooses the site for the World Congress of Endoscopic Surgery. SAGES has hosted this meeting several times in the past, most recently in Washington, D.C. in conjunction with CAGS, the Canadian Association of General Surgery. We had a such a great experience in D.C. that we look forward to working with CAGS again and are making plans to host another joint meeting in the next few years. We also have enjoyed a long association with EAES, the European Association of Endoscopic Surgery. Through our combined efforts, Surgical Endoscopy, the official journal of both societies, has a rising impact factor. Mark Talamini and Sir Alfred Cushieri lead the effort to make this collaboration recognized as one of the top surgical journals in the world. I encourage you to send your best papers in this field to this journal for consideration.

In addition to CAGS in the north, we enjoy strong collaborations with our neighbors in the south. SAGES, through the efforts of the program committee, has hosted joint symposia with ALACE and FILAC, the leading

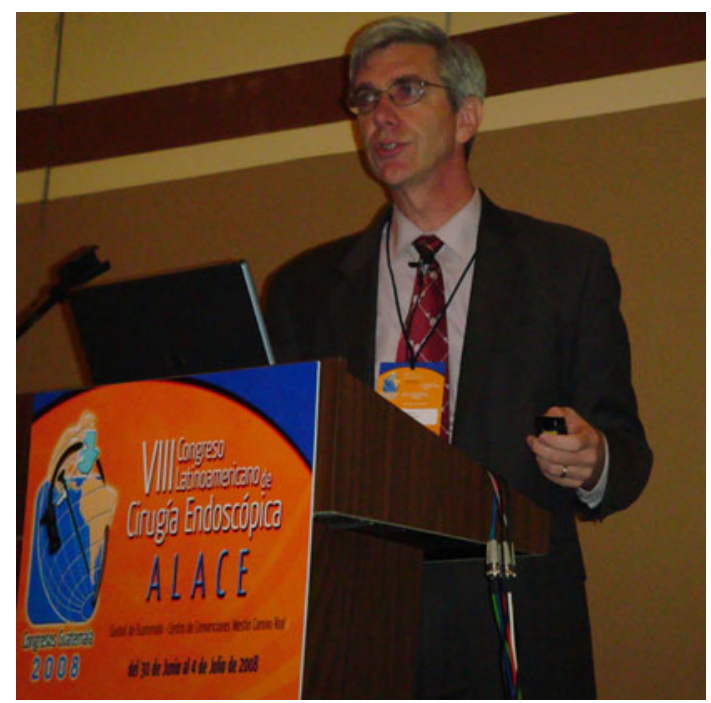

Fig. 4 SAGES past president, Mark Talamini, MD, lectures in Guatemala City at ALACE-SAGES symposium

societies in Latin America but also with the national surgical societies in Guatemala, Brazil, and Colombia in recent years (Fig. 4). Many thanks to Mark Talamini, Steve Eubanks, Jeff Marks, Mike Brunt, Dan Herron, Ted Trus, and Brian Dunkin, for taking the time to serve as SAGES' ambassadors in this effort with some of our closest neighbors. Much of the credit for this belongs to Natan Zundel who is both a SAGES member and former ALACE president. He has been unfailing in efforts to make the world a smaller place (Fig. 4).

If any of you have been to a SAGES Sing-off then you have seen Manabu Yamamoto and his team in action (Fig. 5). As a member of both SAGES and the Japanese Society of Endoscopic Surgery (JSES), Manabu has helped to forge strong bonds between our groups. A series of SAGES-JSES reciprocal symposia have been held at our

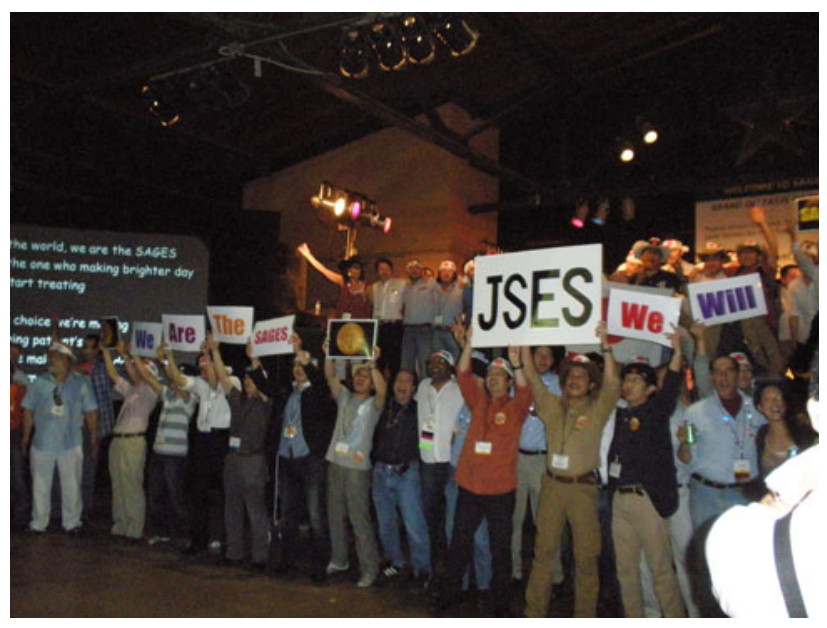

Fig. 5 SAGES sing-off finale lead by members of the JSES 
annual meeting as well as recent JSES meetings in Sendai (devastated by the recent tsunami) and Yokohama. These symposia have focused on comparing the treatments of similar diseases in both the east and west. Many who attended have marveled how both similar and different the care for these patients can be. The efforts of Sergio Larache, Scott Melvin, Horacio Asbun, Dan Jones, Nat Soper, as well as our JSES colleagues like Manubu, Segio Kitano, Masaki Kitajima, and Go Wakabayashi have made these programs a huge success. Our efforts in Asia have recently extended to China. A recent invitation was extended to SAGES by the Chinese Society for Surgery (CSS) to attend a recent surgical meeting in Beijing. Joint sessions discussing SAGES educational programs, MIS complications, hernia, hepatobiliary surgery, and bariatrics were held. Lectures were given by CSS surgeons and SAGES members Aurora Pryor, Allan Okrainec, Horacio Asbun, and Dan Herron. This was our first interaction with the CSS and we hope it will lead to future collaboration in the years to come (Fig. 6).

\section{Volunteerism}

If you attended the SAGES meeting in San Antonio, then you could not help but be moved by the powerful Presidential Address by SAGES president Jo Buyske and Marks Lecturer by Cam Wright (Fig. 7). Jo reminded us that SAGES members have been bestowed with extraordinary gifts of talent and resource. As a result, we must give of ourselves to those less fortunate. During her presidency, she established the Humanitarian Taskforce, which is led by Tonia Young-Fadok. Contributions of human capital can be small or large. SAGES members volunteered to help build homes with Habitat for Humanity for a day in San Antonio (Fig. 8). SAGES' Humanitarian Committee is working with Partners In Health (PIH) to develop the Mirebalis Hospital as a teaching medical center in Haiti.

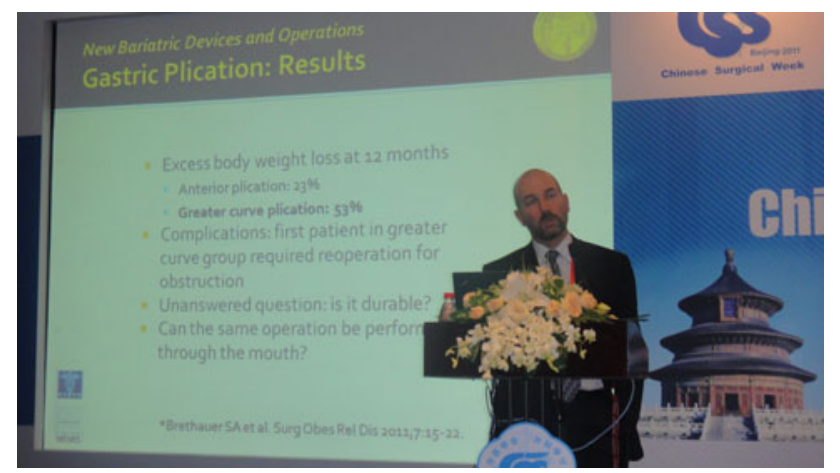

Fig. 6 Dan Herron, MD, lectures at the Joint SAGES-CSS symposium in Beijing, China
SAGES has almost completed work developing a donation registry to seek surgical equipment from industry. We are partnering with PIH to help equip the hospital. Once the hospital is up and running, SAGES will help to create a general surgical and MIS curriculum, provide enduring materials and send faculty to actually train the trainers. The hospital should be ready to receive equipment by November. Let Barbara Berci (Barbara@sages.org) or Tonia Young-Fadok know if you are interested in making a donation. Cam Wright demonstrated a profound depth of commitment when he volunteered to join the reserves to serve in the same theater of operations as his son in the middle east. When he finished his presentation, the room was silent. It was a surreal moment of remarkable energy and feeling. As a former reservist deployed to the Middle East, I can assure you that as a surgeon there are no issues of ideology. I joined the reserves in 1987 after my surgical training was complete with only one idea in mind. I had

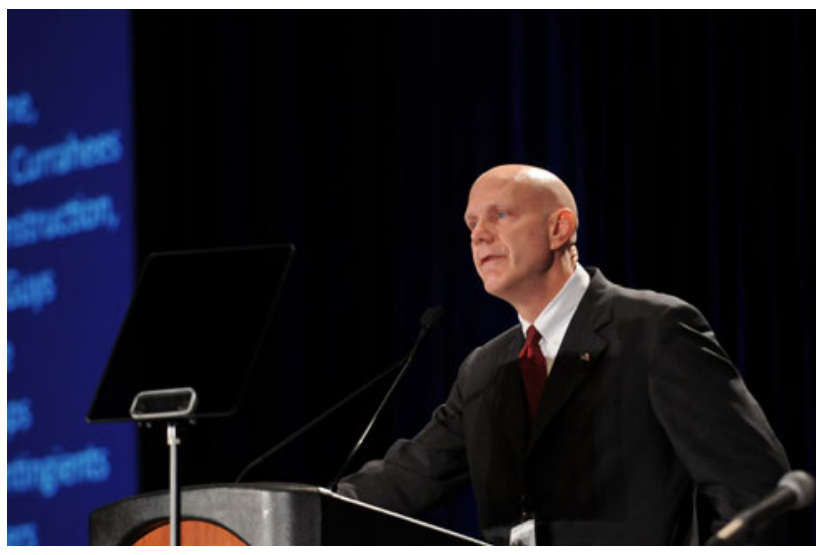

Fig. 7 Cam Wright, MD, speaks at the 2011 Marks Lecture on the nature of battlefield surgical care

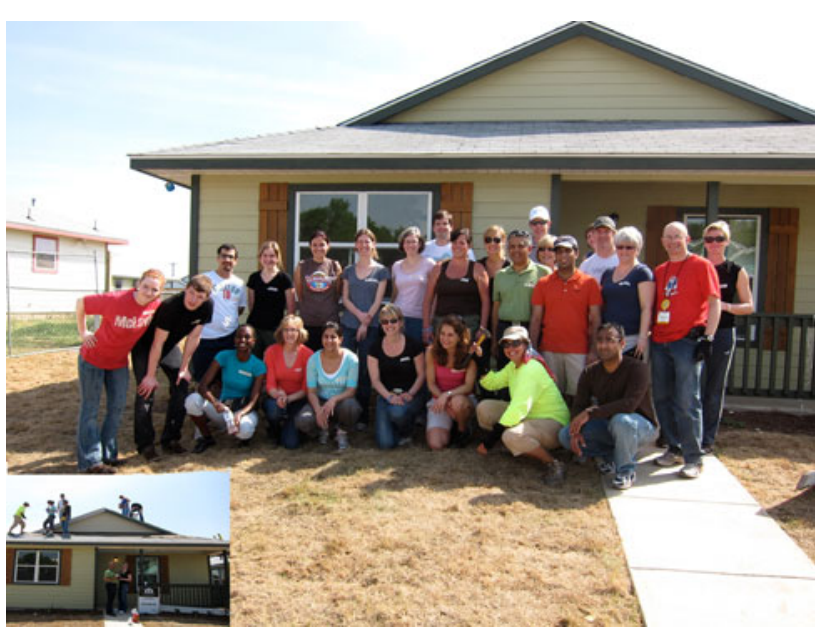

Fig. 8 The SAGES team volunteers for Habitat for Humanity at the 2011 SAGES meeting in San Antonio, Texas 
been the beneficiary of a marvelous education with the skills needed to help young soldiers who fall into harm's way. It was one way of giving back. It worked for me, but have you thought about what might work for YOU? If not, I hope you will. All of today's soldiers are volunteers. SAGES recognizes these efforts through our Military Working Group led by Rob Lim (Army) and Charlie Godinez (Navy). Charlie is both a MIS surgeon and a jet fighter pilot (eat your heart out Maverick). The taskforce has been busy. They have done "live from the battle field" presentations at recent SAGES meetings. In addition, this group is working on issues of transition for soldiers returning from international deployment dealing with issues, such as "How do you keep your MIS skills sharp in the field so you can function safely when you get back home?" Thank you for your service.

\section{SAGES as a Global Society: is there value?}

While the world is getting smaller, it also is changing in ways we are not entirely used to here in the United States. We will have to share the stage of "first nations" with others emerging in these chaotic times. The economic realities of the world are harsh, but it's not just that. We will have to overcome our myopic tendencies. "Every man takes the limits of his own field of vision for the limits of the world." My friends, innovation is taking root in every corner of the globe. We will miss these exciting opportunities if we retreat into our own shell frustrated by bureaucracy, the payers, or our own unwillingness to look past our noses to learn what is happening beyond our borders. We must not tell people around the globe what they need to know; rather, we need to ask what they might like to learn from us. Yes, we still have a lot that we can teach, but equally we have a lot that we can learn. Have you any idea how to practice in a 7,000 bed hospital? Do you know where the per oral endoscopic myotomy (POEM) was developed? Could you reduce the (actual) cost of your case by $50 \%$ without reducing quality? How many U.S. surgeons have performed 1,000 minimally invasive gastrectomies or 500 laparoscopic hepatectomies? Why haven't U.S. surgeons performed the more than 2,000 NOTES cholecystectomies as they have in South America and Europe?

We need to be excellent worldwide partners if our patients are going to realize all of the opportunities available. We have made terrific strides, but there is still more that we can do. For instance, FLS remains the premier validated laparoscopic didactic/skills training program worldwide. Some countries, such as Australia, have strong FLS adoption. What about non-English nations? We have found that skill training transcends language barriers as I noted earlier, but the didactic test, in reality, is an Englishlanguage exam for many competent surgeons who have attempted it. It is not a simple matter of translation. The new material would have to be revalidated if it is to carry the same gravitas in other parts of the world. We also would have to find ways to provide the same examination security as we have here. None of this is easy or inexpensive, but it is not insurmountable or rocket science either. Perhaps we should find a way.

Several years ago SAGES changed its name (but not its acronym) by inserting the word "and" to reflect the idea that we are not just a video-controlled surgery group but a GI society as well. This was prescient leadership as we have grown in body and stature since. I would ask you to consider something a bit more subtle and ponder what the term "American" in our name could mean. The Americas span from nearly the north pole to the tip of Chile. It may seem simplistic, but the first step to becoming a real global partner is to change the way we look at ourselves, perhaps starting by interpreting our name more broadly. Building these global partnerships can only enhance the outcomes for our patients here at home. After all, the world is becoming a smaller place.

Disclosure Steven Schwaitzberg has served on and as a consultant to Endocore during the past 3 years. He has ongoing consultant activities with Olympus, Stryker, Surgiquest, Neatstitch, Cambridge Endo, and Acuity Bio. 